\title{
Composition, Stability and Probable Structure of a Colourless Organometallic Complex (Gd(III)-Malic Acid)
}

\author{
Mohammed Riri $^{1 *}$, Oussama Kamal ${ }^{1}$, Abdelkhalek Benjjar ${ }^{1}$, Farid Serdaoui $^{1}$, Miloudi Hlaibi ${ }^{1,2}$ \\ ${ }^{1}$ Laboratoire d'Interface Matériaux et Chimie de l'Environnement, Université Hassan II Faculté des Sciences Aïn Chock, \\ Casablanca, Maroc \\ ${ }^{2}$ Laboratoire des Polymères, Biopolymères, Surfaces, Faculté des Sciences, Université de Rouen, Rouen, France \\ Email:"mohammedriri@yahoo.fr,miloudi58@hotmail.com
}

Received May 20, 2012; revised June 25, 2012; accepted July 28, 2012

\begin{abstract}
The formation of colourless gadolinium complexes $(x, y, z)$, between $x$ gadolinium ions, $y$ ligands and $z$ protons, of some organic acids, has been studied in aqueous solution. In this work we present the results of investigations on the interaction of the gadolinium ion $\left(G d^{3+}\right)$ with malic acid $\left(\mathrm{C}_{4} \mathrm{H}_{6} \mathrm{O}_{5}, \alpha\right.$-hydroxyl dicarboxylic acid), in dilute aqueous solution for $\mathrm{pH}$ values between 5.5 and 7.5. Colourless gadolinium complexes of malate ions have no absorption band UV-visible, the indirect photometric detection (IPD) technique was used and studies have identified a major tri-nuclear complex of malate ion ( $\left.{ }^{-} \mathrm{OOC}-\mathrm{CH}_{2}-\mathrm{CHOH}-\mathrm{COO}^{-}\right)$. The formation of this new colourless complex is derived from three $\mathrm{Gd}(\mathrm{III})$ ions that react with two malate ions and two hydronium ions $\left(\mathrm{H}_{3} \mathrm{O}^{+}\right)$, giving for this colourless complex, a $(3,2,2)$ composition and apparent stability constant depends on the acidity of the medium, with $\log K_{322}^{\prime}=18.88 \pm 0.05$ at $\mathrm{pH}=6.30$. To complement previous results and to propose a probable structure for this new complex detected in solution, studies of IR spectroscopy have been conducted to identify the chelation sites for both ligands. The results were analysed and show that this organometallic gadolinium complex, contains two different sites, respectively, two lateral tetradentate mono-nuclear sites and a single central bidentate mono-nuclear site. From these results, the reaction of formation, the stability constant and the probable structure of this new colourless organometallic gadolinium complex are proposed.
\end{abstract}

Keywords: Gadolinium Complexes; Malate Ions; Indirect Photometric Detection (IPD); Apparent Stability Constant; Chelation Sites; Bidentate Mono-Nuclear; Tetradentate Mono-Nuclear

\section{Introduction}

In the field of analysis of very dilute solutions, we developed a new detection technique for determining the compositions and stabilities of some colourless organomet-allic complexes, which have no absorption band UV-visible. This technique is the indirect photometric detection (IPD), based on competitive reactions, by ligand-ligand exchange. The method is simple, reproducible, effective and applicable to very dilute solutions. Thus, the importance of IPD technique was also revealed by its adaptation to other techniques of separation and determination, such as liquid chromatography [1-3], capillary electrophoresis [4] and continuous flow analysis (FIA) [5-7]. Some studies [8,9] show that this technique is very effective in identifying some colourless tungstate complexes of sugars and organic acids.

The paramagnetic complexes of the trivalent gadolinium ion $\left(G d^{3+}\right)$, have emerged as very important agents of contrast, for many applications in Magnetic

${ }^{*}$ Corresponding author.
Resonance Imaging (MRI), through interest electronic and magnetic properties of this ion [10,11]. Recent studies have shown that the lanthanide complexes of coumarin (1,2-benzopyrone), exhibit antiproliferative activity [12]. In this work, investigations by indirect photometric detection (IPD) were carried out to study the interaction of the trivalent gadolinium ions, with malate ions (conjugate base of malic acid), detecting the majority of colourless complex formed in solution and determine its composition and stability. To elucidate the structure and the chelation sites of this major malate complex of $G d^{3+}$ ions, the technique of IR spectroscopy has been used. Indeed, these two techniques (IPD and IR spectroscopy) are very useful for elucidating the formation reaction of the major complex for the system $(\mathrm{Gd}$ (III)-malic acid), completely, determine, the composition and stability, the nature of chelation sites for each of ligands ( ${ }^{-} \mathrm{OOC}-\mathrm{CHOH}-\mathrm{COO}^{-}$), involved in the composition of detected complex and propose a probable structure for this major gadolinium complex of the malate ion. 


\section{Experimental Methods}

\subsection{Chemicals}

Malic acid, Chrome Azurol S $\left(\mathrm{H}_{4} \mathrm{Ch}\right)$, Gd(III) nitrate and other chemicals were commercial products (Aldrich, Prolabo,...) of the purest available and analytical grade, used as received.

\subsection{Indirect Photometric Detection}

A standard Helios $\gamma$ UV-visible spectrum-eter controlled by Vision 32 software was used for spectrometric measurements, using quartz cells of optical path length $l=1 \mathrm{~cm}$. The absorption measurements have been performed at room temperature and at wavelength $\lambda_{\text {max }}=545 \mathrm{~nm}$. Stock solutions of Gd(III) nitrate and Chrome Azurol S $\left(\mathrm{H}_{4} \mathrm{Ch}\right)$, prepared with concentrations of respectively $10^{-2} \mathrm{M}$ and $10^{-3} \mathrm{M}$. In a typical experiment, a solution $(v=50 \mathrm{~mL})$ of the colored sacrificial complex $\left(\mathrm{GdH}_{4} \mathrm{Ch}\right)$ was prepared

$$
\left(\left[G d^{3+}\right] /\left[H_{4} C h\right]=1.5\right),
$$

using as a buffer of MESH (0.1 M) [2-(N-morpholino) sulphonic ethane acid]. The initial solution also contained a calculated amount of $1 \mathrm{M} \mathrm{NaOH}$ in order to obtain the desired $\mathrm{pH}$ value $p K_{a(M E S H)}=6.20$, experimental $\mathrm{pH}$ range $(5.5$ - 7.5). $\mathrm{pH}$ values are measured with a Microprocessor $\mathrm{pH}$ Meter HANNA 210 equipped with a combined glass electrode and calibrated with comercial buffers $(\mathrm{pH} \quad 4.00$ and 7.00). Then aliquots $(v=0.100-0.200 \mathrm{~mL})$ of an aqueous solution of the malic acid $\left(C_{L}=2 \mathrm{~g} / L\right)$ were added, using a Gilson micropipet of $0.200 \mathrm{~mL}$. After each addition, the resulting solution was left at least $5 \mathrm{~min}$ in order to reach equilibrium (and thus a constant absorption value). Addition was repeated until a maximum volume of $2.00 \mathrm{~mL}$ of the organic acid solution was added. The change in the total volume was neglected. For fixed $\mathrm{pH}$ environments, the apparent formation constants $\log K_{x y z}^{\prime} \quad$ was calculated using a laboratory made computer program. The absorption values for the undissociated $\left(A_{F}\right)$ and the totally dissociated $\left(A_{I}\right)$, sacrificial complex $\left(G d H_{4} C h\right)$, are used as determined in experiments using pure Chrome Azurol S $\left(\mathrm{H}_{4} \mathrm{Ch}\right)$, and an excess of Gadolinium(III) (performed at $\mathrm{pH}$ intervals of 0.20 ). Assuming various integers for the Gadolinium and organic acid stoichiometry, a formation constant is calculated for each added amount of ligand and corresponding absorption value. The results are rejected when a systematic variation of $\log K_{x y z}^{\prime}$ occurs with increasing added amount of ligand or when individual values of $\log K_{x y z}^{\prime}$ differed from the mean value by more than $2 \%$.

\subsection{IR Spectroscopy}

Samples were prepared by weighing the appropriate amount of malic acid (ligand) and $\mathrm{Gd}\left(\mathrm{NO}_{3}\right)_{3}$ adding $\mathrm{H}_{2} \mathrm{O}$, mixing and finally adjusting the $\mathrm{pH}$ with concentrated $\mathrm{HCl}$ or $\mathrm{NaOH}$ and concentrations of analyzed samples are $10^{-3} \mathrm{M}$. Analyses were performed using an infrared spectrometer, Fourier transform (FT-IR), Perkin Elmer BX, equipped with a DTGS detector, a splitter and a cesium iodide window. In this configuration, the interval of analysis is that the middle infrared, $6000 \mathrm{~cm}^{-1}$ to $250 \mathrm{~cm}^{-1}$ and analysis are conducted on small samples, whose size is less than $1 \mathrm{~mm}^{3}$. Liquid samples are placed between two plates of very pure salt $(\mathrm{KBr})$, these plates are transparent to infrared light and the spectra relative to free ligand (malate ion) and complexed, have been plotted for frequencies from $4400 \mathrm{~cm}^{-1}$ to $400 \mathrm{~cm}^{-1}$.

\subsection{Raman Spectroscopy}

The complex is precepts quickly at room temperature, at a concentration of $10^{-2} \mathrm{M}$ and fixed $\mathrm{pH}$ value (5.86) (Higher than the acidity constant of malic acid). The precipitate was filtered and dried in drying oven and the complex formed is insoluble in water, methanol and ethanol. The Raman spectra of the ligand (Malic acid) and its new Gd(III) complex was performed using an Fourier transformation Raman spectrometer (FT-Raman) VERTEX 70 with a range of measurement (4000 - 50) $\mathrm{cm}^{-1}$, laser source NdYag $(1.064 \mu \mathrm{m})$, a nominal power of $500 \mathrm{MW}$, detecting Ge with high sensitivity and a resolution of $4 \mathrm{~cm}^{-1}$ (64 scan). The spectra relative to free malic acid and Gd(III)-carboxylate complex, have been plotted for frequencies from $3600 \mathrm{~cm}^{-1}$ to $200 \mathrm{~cm}^{-1}$.

\section{Results and Discussion}

\subsection{Indirect Photometric Detection Study}

The complexation reaction of $x$ gadolinium ions $\left(G d^{3+}\right)$ with $y$ malate ions and $z$ protons $\left(H^{+}\right)$, is given by expression (I):

$$
x G d^{3+}+y L^{2-}+z H^{+} \rightleftarrows(x, y, z)+n \mathrm{H}_{2} \mathrm{O}(I)
$$

$L^{2-}$ represents the ligand (malate ion).

The formation constant $K_{x y z}$ (or stability constant $\left(\beta_{x y z}\right)$ of the complex is defined as the equilibrium constant :

$$
K_{x y z}=[(x, y, z)] \cdot\left[G d^{3+}\right]^{-x} \cdot\left[L^{2-}\right]^{-y} \cdot\left[H^{+}\right]^{-z}
$$

Additionally, a conditional equilibrium constant $K_{x y z}$ is defined in case of constant $\mathrm{pH}$ value (buffered solution):

$$
K_{x y z}^{\prime}=[(x, y, z)] \cdot\left[G d^{3+}\right]^{-x} \cdot\left(C_{L}\right)^{-y}
$$

$C_{L}$ represents the analytical concentration of the un- 
complexed ligand, all experiments are performed for $\mathrm{pH}$ values higher than $p K_{a 1}$ and $p K_{a 2}$ of malic acid, therefore, we have $C_{L}=\left[L^{2-}\right]$. Using this equality, Equation 1 can be written as:

$$
\begin{aligned}
K_{x y z} & =[(x, y, z)] \cdot\left[G d^{3+}\right]^{-x} \cdot\left(C_{L}\right)^{-y} \cdot\left[H^{+}\right]^{-z} \\
& =K_{x y z}^{\prime}\left[H^{+}\right]^{-z}
\end{aligned}
$$

Thus $\log K_{x y z}=\log K_{x y z}^{\prime}+z \cdot p H$

The complexation of the ligand can be studied using a spectrophotometric method. Since the reagent (malic acid) and its detected gadolinium complex do not possess a characteristic UV-visible absorption spectrum, a second ligand (called the sacrificial ligand) is introduced. This second ligand must absorb in the UV-visible spectrum and form a colored complex with $G d^{3+}$ ions. Based on ligand-ligand displacement, the photometric method is said to be in the indirect mode. The dissociation of this colored complex has to cause large variations in the UVvisible spectrum which allow the calculation of the concentration of the sacrificial complex. Using the formation constant of this colored complex, the concentration of the unknown complex can be obtained. Therefore, the sacrificial ligand must form a single colored complex of lower stability than the gadolinium complex under study. In this work, 3"'-sulfo-2",6"-dichloro-3,3'-dimeth-yl-4'-hydroxy-fuchsone-5,5'-dicarboxylic acid, often called Chrome Azurol $\mathbf{S}$ and noted $\mathrm{H}_{4} \mathrm{Ch}$, has been used as sacrificial ligand. Chrome Azurol $\mathrm{S}$ is a tetraprotic acid with $\mathrm{pKa}$ values of $2.25\left(\mathrm{H}_{3} \mathrm{Ch}^{-} / \mathrm{H}_{2} \mathrm{Ch}^{2-}\right), 4.71$ $\left(\mathrm{H}_{2} \mathrm{Ch}^{2-} / \mathrm{HCh}^{3-}\right)$ and $11.82\left(\mathrm{HCh}^{3-} / \mathrm{Ch}^{4-}\right)$ [13]. In the experimental $\mathrm{pH}$ range $(5.5-7.5)$, the formation of $\mathrm{H}_{4} \mathrm{Ch}, \mathrm{H}_{3} \mathrm{Ch}^{-}$and $\mathrm{H}_{2} \mathrm{Ch}^{2-}$ has been neglected. It is an indicator which is generally used for the photometric proportioning of the metal ions in solution $[14,15]$. The interaction of the $\mathrm{H}_{4} \mathrm{Ch}$ with gadolinium ions $\left(G d^{3+}\right)$, gives a coloured reagent $\left(\lambda_{\max }=545 \mathrm{~nm}\right)$ of average stability for values of $\mathrm{pH}$ ranging between 5.50 and 7.50. The buffer "MESH". [2-(N-morpholino) sulphonic ethane acid] was adopted to fix $\mathrm{pH}$ in the study of the sacrificial complex $\mathrm{Gd}-\mathrm{H}_{4} \mathrm{Ch}$ and the detected gadolinium-malate complex. We chosed this buffer because it does not present any interaction with $G d^{3+}$ ions and so that we would be able to work in range of $\mathrm{pH}$ where the stability of the sacrificial complex is maximal.

\subsection{Formation of the Colored Sacrificial Complex $\boldsymbol{G d}_{\boldsymbol{x}}(\mathrm{HCh})_{y}$}

A series of experiments was conducted to determine, the composition, the stability of the colored sacrificial complex $\left(G d_{x}(H C h)_{y}\right)$ and its formation reaction. Indeed, in $50 \mathrm{~cm}^{-3}$ of the auxiliary ligand solution $\left(\mathrm{HCh}^{3-}\right)$ of a concentration $C_{H C h}=10^{-4} \mathrm{M}$ and $\mathrm{pH}=5.91$, we in- troduced increasing quantities of a $G d^{3+}$ ions solution of initial concentration $10^{-2} \mathrm{M}$. The evolution of UVvisible spectra for the formation of this sacrificial complex is represented by the diagram in following Figure 1.

The UV-visible spectra show clearly that the maximum absorbance of the sacrificial complex is located at $\lambda_{\text {max }}=545 \mathrm{~nm}$. So, we have studied the formation of this sacrificial complex at this maximum wavelength, depending on the ratio

$$
q=(\text { metal } / \text { ligand })=\left[G d^{3+}\right] /\left[H C h^{3-}\right]_{\text {total }}
$$

as shown in the Figure 2.

The curve in Figure 2 indicates that the value of the ratio $\mathrm{q}$, relative to the complete formation of this sacrificial complex is the intersection of the linear (positive slope), with the final segment (slope $=0$ ) of the curve, this value of $q$ is close to 1.50 . This indicates that the

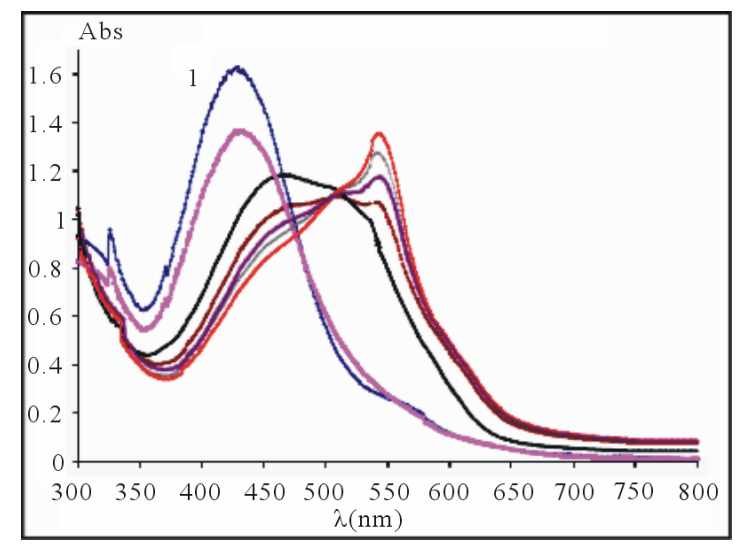

Figure 1. UV-visible spectra for the formation of sacrificial complex $G d_{x}(H C h)_{y}, \mathrm{pH}=5.91,\left[\mathrm{HCh}^{3-}\right]_{\text {total }}=10^{-4} \mathrm{M}$ and $\left[G d^{3+}\right]_{0}=10^{-2} \mathrm{M}, I=1 \mathrm{~cm}$, Curve (1) free CAS.

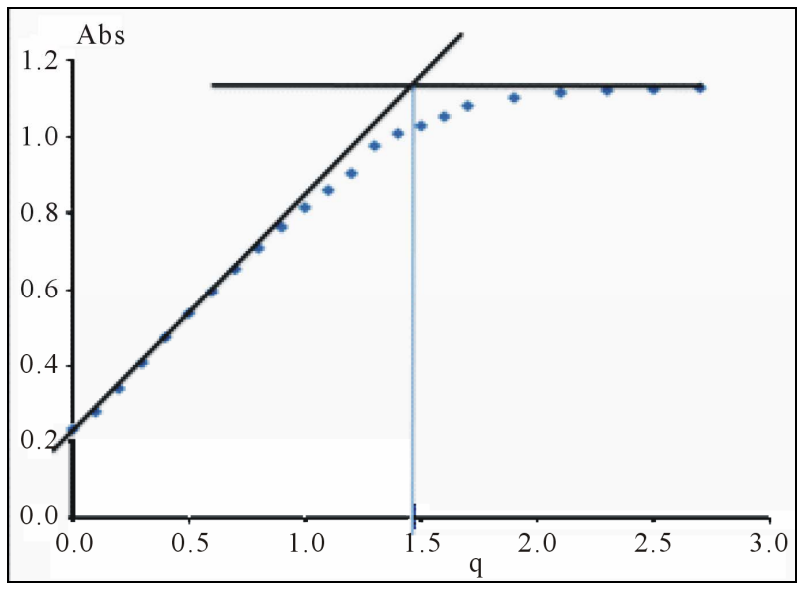

Figure 2. Formation of the sacrificial complex, depending on the ratio $\boldsymbol{q}=\left[\boldsymbol{G d}^{3+}\right] /\left[\mathrm{HCh}^{3-}\right]_{\text {total }}$, buffer $\mathrm{MES}^{-} / \mathrm{MESH}$, $\mathrm{pH}=5.70, \lambda_{\max }=545 \mathrm{~nm}, I=1 \mathrm{~cm},\left[\mathrm{HCh}^{3-}\right]_{\text {total }}=10^{-4} \mathrm{M}$. 
formation of the sacrificial complex is according to the following balanced reaction:

$$
\begin{gathered}
x G d^{3+}+y H C h^{3-}+z H^{+} \rightleftarrows(x, y, z)+n \mathrm{H}_{2} \mathrm{O}(I I) \\
1.5 C_{H C h} C_{H C h} \text { fixed } 0 \\
C_{H C h}(1.5-x \alpha) \quad C_{H C h}(1-x \alpha) \quad \alpha C_{H C h}
\end{gathered}
$$

$C_{H C h}$ represents the analytical concentration of ligand $\mathrm{HCh}^{3-}$ in all its forms, $\mathbf{z}$ the number of protons involved during the reaction, while $C_{H C h}$ is the coefficient of complex formation, calculated from the experimental values of absorbance by the relation $\alpha=\left(A-A_{I}\right) /\left(A_{F}-A_{I}\right)$, with $A_{I}$ and $A_{F}$ which respectively represent the initial absorbance (free ligand) and final (100\% of the complex).

Therefore, the expression of the apparent constant on the formation reaction according to the balanced reaction (II) is given by the following equation :

$$
\begin{aligned}
K_{x, y, z}^{\prime} & =[(x, y, z)] \cdot\left[G d^{3+}\right]^{x} \cdot\left(C_{H C h}\right)^{y} \\
& =\alpha\left(C_{H C h}\right)^{1-x-y} /(1.5-x \alpha)^{x} \cdot(1-y \alpha)^{y}
\end{aligned}
$$

$K_{x, y, z}^{\prime}$ is calculated using a computer program written from the balanced reaction (II), we obtained constant values of $K_{32 z}^{\prime}$ for the pair $(x=3, y=2)$ for all experimental points, with a value of $\log K_{32 z}^{\prime}=7.40$ at $p H=5.91$. Under the same conditions of temperature and concentrations, several experiments were performed for $\mathrm{pH}$ values between 5.50 and 7.50. The same calculation program was used and the results clearly indicate that only the detected sacrificial complex $(3,2, z)$, is formed in solution. For all studied solutions at known values of $\mathrm{pH}$, the apparent constants $K_{32 z}^{\prime}$ were calculated and the obtained results are summarized in the Table 1. These results show that the stability of the sacrificial complex depends on the acidity of the medium.

For all these solutions, the formation constant $K_{32 z}^{\prime}$ on the sacrificial complex is given by the relationship $K_{x y z}^{\prime}=K_{32 z}^{\prime} /\left[H^{+}\right]^{z}$. Hence $\log K_{32 z}=\log K_{32 z}^{\prime}+z \cdot p H$, ( $K_{32 z}^{\prime}$ conditional constant for a given $\mathrm{pH}$ ), we plot the curve $\log K_{32 z}^{\prime}$ depending on the medium $\mathrm{pH}$ (Figure 3), and the slope value is the equivalent number of $\mathrm{H}^{+}$ ions that react, with 1.5 equivalents of $G d^{3+}$ ions and 1 equivalent of $\mathrm{HCh}^{3-}$ ions (composition adopted to make simple calculations). The linear function shown in Figure 3, clearly verifies the accuracy of the studied relationship, and its slope $p=1.50$, calculates the equivalent number of hydronium ions, involved in the formation reaction of the detected gadolinium complex, and hence determines it exact composition $(3,2,3)$, whereas the intercept expresses the stability constant of this sacrificial complex, with $\log K_{x y z}=16.27$ at V.

Thus, the complexation of $G d^{3+}$ ions by $\mathrm{HCh}^{3-}$ ions in the $\mathrm{pH}$ range 5.50 to 7.50 , led to the formation of the colored tri-nuclear complex, by following balanced reaction:

$$
3 \mathrm{Gd}^{3+}+2 \mathrm{HCh}^{3-}+3 \mathrm{H}^{+} \rightleftarrows(3,2,3)+3 \mathrm{H}_{2} \mathrm{O}
$$

The formation constant of this $(3,2,3)$ complex is defined as:

$$
K_{323}=[(3,2,3)] \cdot\left[G d^{3+}\right]^{-3} \cdot\left[H C h^{3-}\right]^{-2} \cdot\left[H^{+}\right]^{-3} .
$$

The conditional equilibrium constant for a fixed value of $\mathrm{pH}$ is given by:

$$
K_{323}=[(3,2,3)] \cdot\left[G d^{3+}\right]^{-3} \cdot\left(C_{H C h}\right)^{-2}
$$

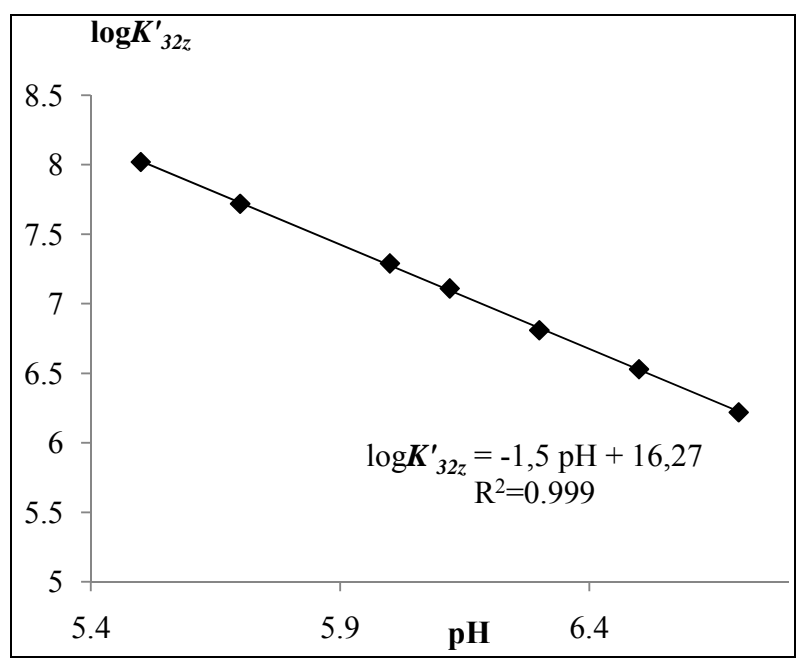

Figure 3. The stability of the tri-nuclear complex $\mathrm{Gd}_{3} \mathrm{HCh}_{2}$ depending on the medium acidity.

Table 1. Evolution of the sacrificial complex stability, depending on the acidity of the medium.

\begin{tabular}{cccccccccc}
\hline $\mathbf{p H}$ & $\mathbf{5 . 5 0}$ & $\mathbf{5 . 7 0}$ & $\mathbf{5 . 9 0}$ & $\mathbf{6 . 0 0}$ & $\mathbf{6 . 1 2}$ & $\mathbf{6 . 3 0}$ & $\mathbf{6 . 5 0}$ & $\mathbf{6 . 7 0}$ \\
\hline $\log K_{32 z}^{\prime} \pm 0.05$ & 8.02 & 7.72 & 7.40 & 7.29 & 7.11 & 6.81 & 6.53 & 6.22 \\
$A_{I}$ & 0.358 & 0.253 & 0.301 & 0.388 & 0.225 & 0.295 & 0.285 & 0.265 \\
$A_{F}$ & 1.0605 & 1.179 & 1.316 & 1.466 & 1.616 & 1.666 & 2.704 & 2.826 \\
$\varepsilon=\left(\mathrm{M}^{-1} \cdot \mathrm{cm}^{-1}\right)$ & 11000 & 12000 & 13000 & 15000 & 16000 & 17000 & 27000 & 28000 \\
\hline
\end{tabular}




\subsection{The Composition and Stability Study of the System: Gd(III)-Malic Acid}

If the studied ligand (malate ions), is added to a colored solution of the sacrificial complex $(3,2,3)$, this chrome azurol S ( $\left.\mathrm{HCh}^{3-}\right)$ complex will dissociate. To calculate the complexed concentration of the $\mathrm{HCh}^{3-}$ ions, the absorption values of the totally complexed $A_{F}$, and completely dissociated $\mathrm{HCh}^{3-}$ ions have to be determined $A_{I}$. Then the following equations can be used:

$$
\begin{aligned}
& {[(3,2,3)]=\left(C_{H C h}\right)_{0} \cdot\left(A-A_{I}\right) /\left(A_{F}-A_{I}\right)} \\
& \left(C_{H C h}\right)_{\text {free }}=\left(C_{H C h}\right)_{0} \cdot\left(A-A_{I}\right) /\left(A_{F}-A_{I}\right)
\end{aligned}
$$

When the conditional equilibrium constant $K_{323}^{\prime}$ of the sacrificial complex is known, the concentration of free gadolinium ion $\left(\left[G d^{3+}\right]\right)$, can be calculated using Equations (7)-(9).

Knowing $[(3,2,3)]$ and $\left[G d^{3+}\right]$, the concentration of the gadolinium complex under study $[(x, y, z)]$ (balanced reaction I) can be determined using the gadolinium mass balance equation :

$$
x \cdot[(3,2,3)]=C_{G d}-[(3,2,3)]-\left[G d^{3+}\right]
$$

$C_{G d}$ being the initial gadolinium concentration. In a similar way, the concentration of the free ligand is obtained by

$$
\left(C_{L^{2-}}\right)_{\text {free }}=\left(C_{L^{2-}}\right)_{0}-y[(x, y, z)]
$$

It should be also noted that a perfect knowledge of the characteristics of the sacrificial colored complex $\mathrm{Gd}_{3} \mathrm{HCh}_{2}$ is necessary. The determination of the composition and the stability of the sacrificial complex and the precision of the conditions of its formation are paramount stages to apply the indirect photometry technique. In each experiment, the ligand (malate ions), is added stepwise in order to measure the absorption at different values (at least 12) of the overall initial concentration of this studied ligand. The correct $K_{x y z}^{\prime}$ is looked for by varying $\boldsymbol{x}$ and $\boldsymbol{y}$ in order to obtain a constant value for all values of $C_{L^{2-}}$. If $K_{x y z}^{\prime}$ is determined at different $\mathrm{pH}$ values, the slope of the $\log K_{x y z}^{\prime} \cdot \mathrm{pH}$ plot reveals the number $\mathbf{z}$ of protons, necessary for the formation of the studied gadolinium complex by use of equation 4 , since the value of $K_{x y z}^{\prime}$ is independent of $\mathrm{pH}$. Now the stability and the total composition of the gadoliniummalate complex have been determined.

\subsection{Determination of the Composition and the Stability Constant of the Gd-Malate}

With an aim of determining the composition and the stability constant of the gadolinium-malate complex, we monitored the evolution of the absorbance during disappearance of the sacrificial complex by addition of increasing quantities of malate ions. For a given volume $(50 \mathrm{ml})$ of a solution containing sacrificial complex $(3,2,3) 10^{-2} \mathrm{M}$, we added increasing quantities of malate ions solution, with known concentration. The spectrophotometric study carried out with fixed wavelength $\left(\lambda_{\max }=545 \mathrm{~nm}\right)$, showed a reduction in the absorbance of the solution progressively with the addition of the malate ions (Figure 4). The dissociation of the sacrificial complex, relating to the reduction in the absorbance by the addition of malate ions solution, is done in favour of the formation of the colourless complex between $G d^{3+}$ and malate ion species.

The curve $C \cdot 2$ in Figure 4, clearly shows that the absorbance decreases and stabilizes. This stability indicates that all $G d^{3+}$ ions, initially present in the solution have reacted with added malate ions. Knowing the concentration of gadolinium ions and the quantity of ligand from the added volume of the malic acid solution, necessary to reach this stage of absorption, we could determine the molar ratio $q\left(G d^{3+} /\right.$ malate $)$, involved in the complexation reaction. The preceding experiment was carried out for different values of $\mathrm{pH}$ between 5.50 and 7.50, the way in which the absorption decreases, depends on the $\mathrm{pH}$ of the medium and on the formation constant of the detected complex (Gd-malate), as well as on the absorption values $\left(A_{I}\right)$ and $\left(A_{F}\right)$ of the free and totally complexed Chrome Azurol S ( $\left.\mathrm{HCh}^{3-}\right)$. Analyzing the experimental data with the computer program written from the balanced reaction (I), the results confirm the reproducibility of the molar ratio $q$ and to determine the composition and apparent stability constant $K_{x y z}^{\prime} \quad$ (Table 2). The data-processing treatment of the preceding experimental results, shows that this tri-nuclear detected complex

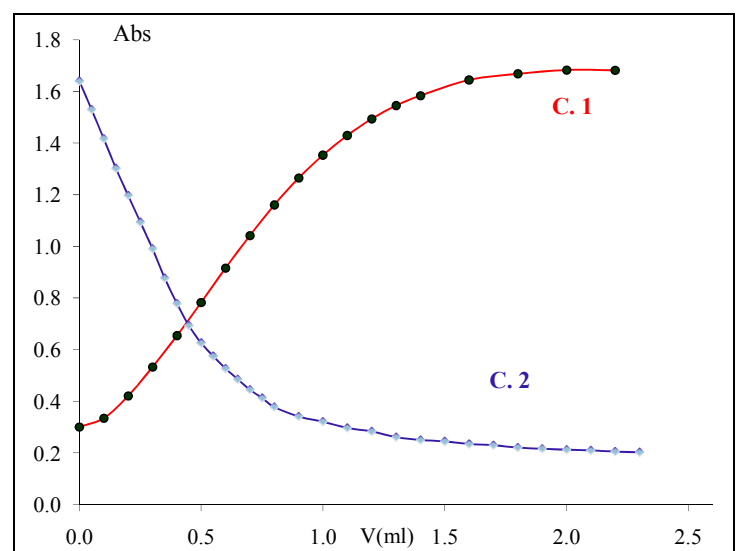

Figure 4. C.1 : Formation of colored sacrificial complex $G d_{3}(H C h)_{2} ; C .2$ : Decomposition of this complex by addition of a malic acid solution $(2 \mathrm{~g} / L), p H=6.50$, $\left[\mathrm{HCh}^{3-}\right]_{\text {total }}=10^{-4} \mathbf{M}, \quad q=\left[\mathrm{Gd}^{3+}\right] /\left[\mathrm{HCh}^{3-}\right]=\mathbf{3} / \mathbf{2}$. 
Table 2. The apparent stability of the tri-nuclear detected complex, depending on the acidity of the medium.

\begin{tabular}{cccccc}
\hline $\mathrm{pH}$ & 5.63 & 5.80 & 6.11 & 6.30 & 6.54 \\
\cline { 1 - 5 } $\log K_{32 z}^{\prime}$ & 20.21 & 19.86 & 19.26 & 18.88 & 18.38 \\
\hline
\end{tabular}

formed between the gadolinium ions and malate ions, resulting from the interaction of three $G d^{3+}$ ions equivalents with two equivalents of malate species, so a molar ratio $q=x(G d) /($ malte $)=3 / 2$.

Buffer $M E S^{-} / M E S H, \lambda_{\max }=545 \mathrm{~nm}, l=1 \mathrm{~cm}$,

$$
\left[\mathrm{HCh}^{3-}\right]_{\text {total }}=10^{-4} \mathrm{M},\left[G d^{3+}\right]_{0}=10^{-2} \mathrm{M}
$$

For all $\mathrm{pH}$ range we obtained $(x=3, y=2)$, therefore, for the complexation reaction of $G d^{3+}$ ions with malate ions at this $\mathrm{pH}$ range, these results and the Equations (1)-(3) allow to write the following expressions:

$$
x G d^{3+}+y L^{2-}+z H^{+} \rightleftarrows(x, y, z)+n \mathrm{H}_{2} \mathrm{O}
$$

The value of $\mathbf{z}$ can be positive, negative or null. The stability constant of this formed complex is defined by:

$$
K_{32 z}=[(3,2, z)] \cdot\left[G d^{3+}\right]^{-3} \cdot\left[L^{2-}\right]^{-2} \cdot\left[H^{+}\right]^{-z}
$$

Conditional stability constant $K_{32 z}^{\prime}$ is defined in case of constant $\mathrm{pH}$ value (buffered solution):

$$
K_{32 z}^{\prime}=[(3,2, z)] \cdot\left[G d^{3+}\right]^{-3} \cdot\left(C_{L}\right)^{-2}
$$

For these experimental $\mathrm{pH}$ values higher than the $p K_{a 1}$ and $p K_{a 2}$ of malic acid, $C_{L}=\left[L^{2-}\right]$ thus:

$$
\begin{aligned}
K_{32 z} & =[(3,2, z)] \cdot\left[G d^{3+}\right]^{-3} \cdot\left(C_{L}\right)^{-2} \cdot\left[H^{+}\right]^{-z} \\
& =K_{32 z}^{\prime} \cdot\left[H^{+}\right]^{-z}
\end{aligned}
$$

And $\log K_{32 z}^{\prime}=\log K_{x y z}-z \cdot p H$

The evolution of $\log K_{32 z}^{\prime}$ at different $\mathrm{pH}$ values is represented on Figure 5, this evolution is linear and the slope of the straight line is equal to -2 . The value $(z=2)$ represents the number of protons involved in the formation reaction of this new tri-nuclear complex $(3,2,3)$

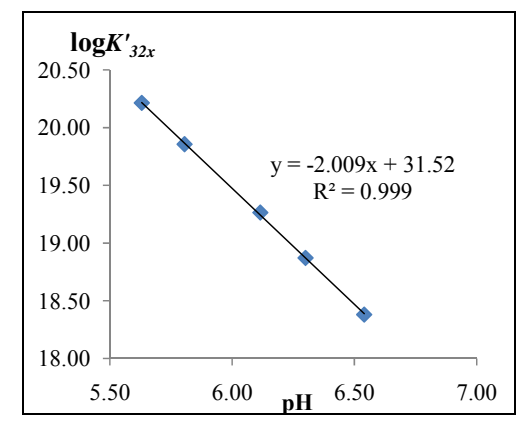

Figure 5. Evolution of $\log K_{\mathrm{xyz}}^{\prime}$ for trinuclear $\mathrm{Gd}(\mathrm{III})$-malate complex, at different $\mathrm{pH}$ values.
(Gadolinium-Malate) species.

\section{Consequently}

In the light of the spectrophotometric results relating to the interaction of $G d^{3+}$ ions with the malate ions, namely that the complexation reaction uses three hydrolyzed $G d^{3+}$ ions for two malate species and requires fixation of two protons.

According to the literature [16], the $G d^{3+}$ ion can be presented in various hydrolyzed forms in aqueous solution and this new tri-nuclear gadolinium complex detected in solution at experimental $\mathrm{pH}$ range, is probably formed from the hydrolyzed form $\mathrm{Gd}(\mathrm{OH})_{2}^{+}$, according to the following reaction:

$$
3 G d(\mathrm{OH})_{2}^{+}+2 L^{2-}+2 \mathrm{H}^{+} \rightleftarrows(3,2,2)^{+}+2 \mathrm{H}_{2} \mathrm{O}
$$

In order to confirm our results, to have more information on the nature of this new gadolinium complex and likely to propose a probable structure for this tri-nuclear specie, we carried out IR spectroscopy investigations. These studies by IR spectroscopy carried out in the same $\mathrm{pH}$ range but with more concentrated solutions, help to identify the nature of the chelation sites and the probable structure of this new gadolinium complex formed by interaction of malate ions with this hydrolyzed form of $G d^{3+}$ ions.

\subsection{IR Spectroscopy Investigations}

The IR spectroscopic studies can identify different groups of malic acid (ligand), which participate in chelation sites for the formation of the detected gadolinium complex. Three dilute solutions $\left(10^{-1} \mathrm{~cm}\right)$, respectively, the free malate ion $(p H=5.60)$, free malic acid $(\mathrm{pH}=2.02)$ and detected gadolinium complex of malate ion $(\mathrm{pH}=$ 5.60), were prepared and their spectra recorded (Figure 6) and analyzed. Table 3 contains bibliographic data [17, 18], relative to vibrations intervals of various groups: $\mathrm{OH}$, $\mathrm{C}=\mathrm{O}, \mathrm{COO}^{-}$and $\mathrm{C}-\mathrm{C}=\mathrm{O}$, and the intervals of vibration on the analyzed spectra (1,2 and 3$)$.

The experimental spectra obtained for the three analyzed samples, clearly indicate that the frequency for vibration of the groups: $\mathrm{OH}, \mathrm{C}=\mathrm{O}$ and $\mathrm{COO}^{-}$, have

Table 3. The vibration frequencies, for the studied spectra and bibliographic data.

\begin{tabular}{ccc}
\hline \multirow{2}{*}{ Groups } & Experimental spectra & Ref. [17,18] \\
\cline { 2 - 3 } & \multicolumn{2}{c}{$v\left(\mathrm{~cm}^{-1}\right)$} \\
\hline $\mathrm{O}-\mathrm{H}$ & $3300-3600$ & $3650-3500$ \\
$\mathrm{C}=\mathrm{O}$ & $1620-1680$ & $1800-1700$ \\
$\mathrm{COO}^{-}$ & $400-900$ & $590-700$ \\
$\mathrm{C}-\mathrm{C}=\mathrm{O}$ & & $465-550$ \\
\hline
\end{tabular}


seriously reduced $75 \%, 80 \%$ and $66 \%$ passing the free to complexed ligand (Figure 6). So, for each of the two malate ions involved in the formation of this detected tri-nuclear complex, the four oxygen atoms of the ionized carboxylic groups, participate in chelation sites, and the $\mathrm{OH}$ group in $\alpha$ position of the ionized group $\mathrm{COO}^{-}$.

\subsection{FT-Raman Spectroscopy Investigations}

FT-Raman spectra of free malic acid and its complex with Gadolinium ions $G d^{3+}$, are shown in Figure 7. A detailed analysis of vibrations in Raman spectroscopy was performed on the basis of comparison of experimenttal vibrational spectra obtained of malic acid and its gadolinium complex. The Raman spectra obtained show that the $\mathrm{OH}$ vibrations $3350 \pm 104 \mathrm{~cm}^{-1}[12,19]$ and the free malic acid present two vibrations of $\mathrm{C}=\mathrm{O}$ at 1677 $\mathrm{cm}^{-1}$ and $1635 \mathrm{~cm}^{-1}$ because the malic acid present two carbonyl functions aren't the same environment $[19,20]$, these vibrations of $\mathrm{OH}$ and $\mathrm{C}=\mathrm{O}$ groups, were not detected in the complex spectra and the vibration of $\mathrm{C}-\mathrm{C}=\mathrm{O}$ group is reduced from free malic acid to its gadolinium complex. So, all oxygen atoms involved in the chelation sites of this new tri-nuclear complex.

The vibration spectra (weak broad) of the complex in $1600 \mathrm{~cm}^{-1}$, indicate the existence of water molecules [21], the intense vibration observed in the complex near 1069 $\mathrm{cm}^{-1}$ indicate the existence of the nitrate ions [12]. The new band vibrations related to Gd(III)-Oxygen carboxylate functions, are located at 600 and $547 \mathrm{~cm}^{-1}$ with a weak bands [21,22], and the strong vibration of Gd(III)oxygen nitrate appeared at $187 \mathrm{~cm}^{-1}$ [23]. The different vibrations (stretching and deformation) of C-C (aliphatic chains) appeared in a long field (1400 $\left.-400 \mathrm{~cm}^{-1}\right)$ with intense and medium intensities [21,20,24]. Bands in the $2590 \pm 80 \mathrm{~cm}^{-1}$ region were assigned to the vibrations of $\mathrm{CH}$ and $\mathrm{CH}_{2}[25,26]$, these bands are moderate intensities in complex spectra

These results clearly indicate that, this new tri-nuclear gadolinium complex contains two types of sites, a single central bidentate mono-nuclear site with participation of only $\mathrm{OH}$ groups in $\alpha$ position and two lateral tetradentate mono-nuclear sites, each consisting of four oxygen atoms of two ionized carboxylic functions, belonging to the two malate ions ( $\mathrm{OOC}-\mathrm{CHOH}-\mathrm{COO}^{-}$), involved in the formation of this new detected gadolinium organometallic complex. Indeed, all these results can offer for this trinuclear $\mathbf{G d}$-Malic acid, the structure presented in Figure 8.

\section{Conclusion}

In this work, we used some techniques to study the interactions of the trivalent $\mathrm{Gd}(\mathrm{III})$ ions with different ionic forms of malic acid and identify the composition, stability and structure of the major colourless complex, formed in solution for $\mathrm{pH}$ values between 5.50 and 7.50. The photometry in indirect mode (IPD) was used successfully to determine the composition and the stability of this major gadolinium complex. Only the tri-nuclear

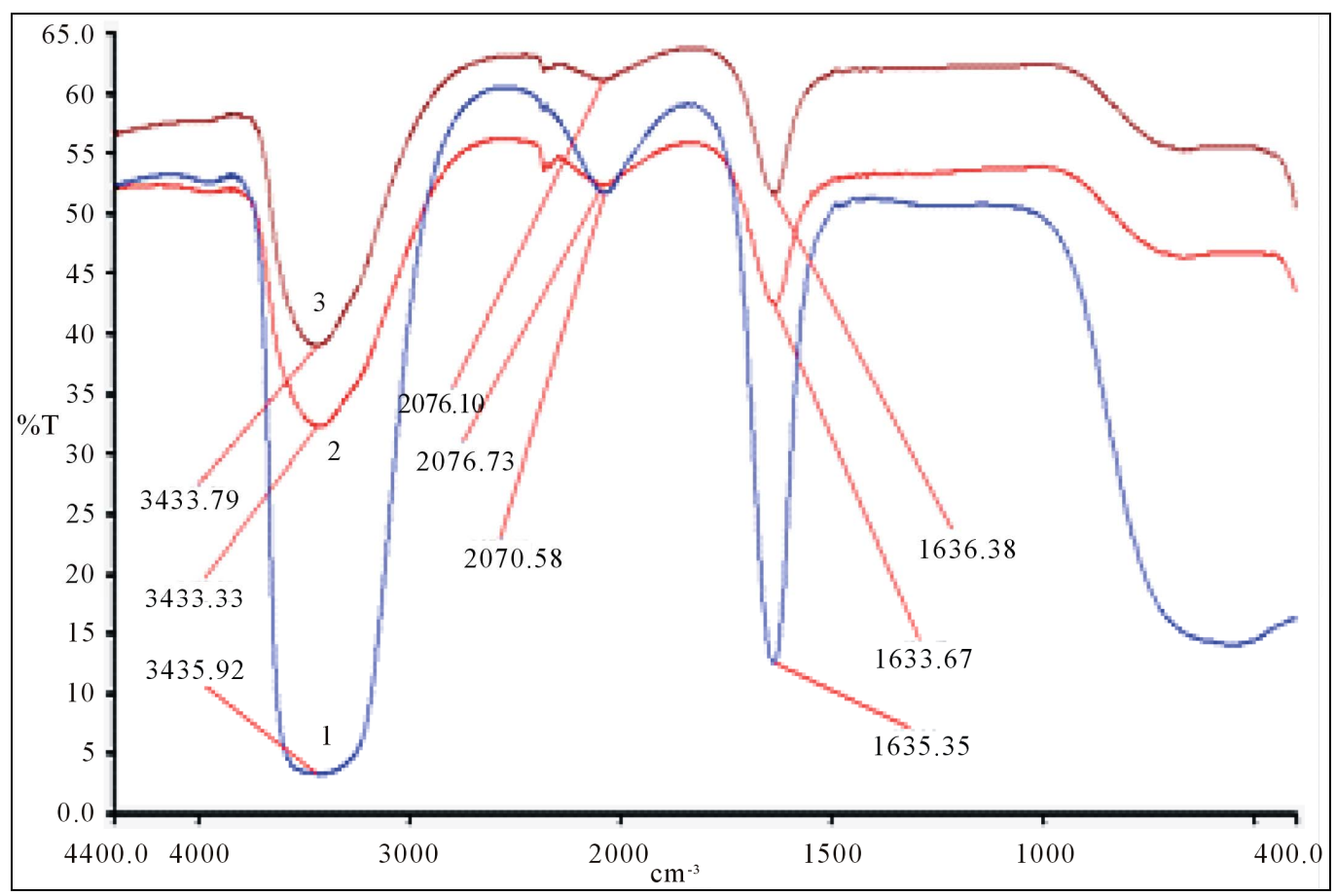

Figure 6. IR spectra, (1) free malate ion $10^{-3} \mathrm{M}$; (2) free malic acid $10^{-3} \mathrm{M} ;(3) \mathrm{Gd}-\mathrm{malate},\left[G d^{3+}\right] /\left[L^{2-}\right]=3 / 2$. 


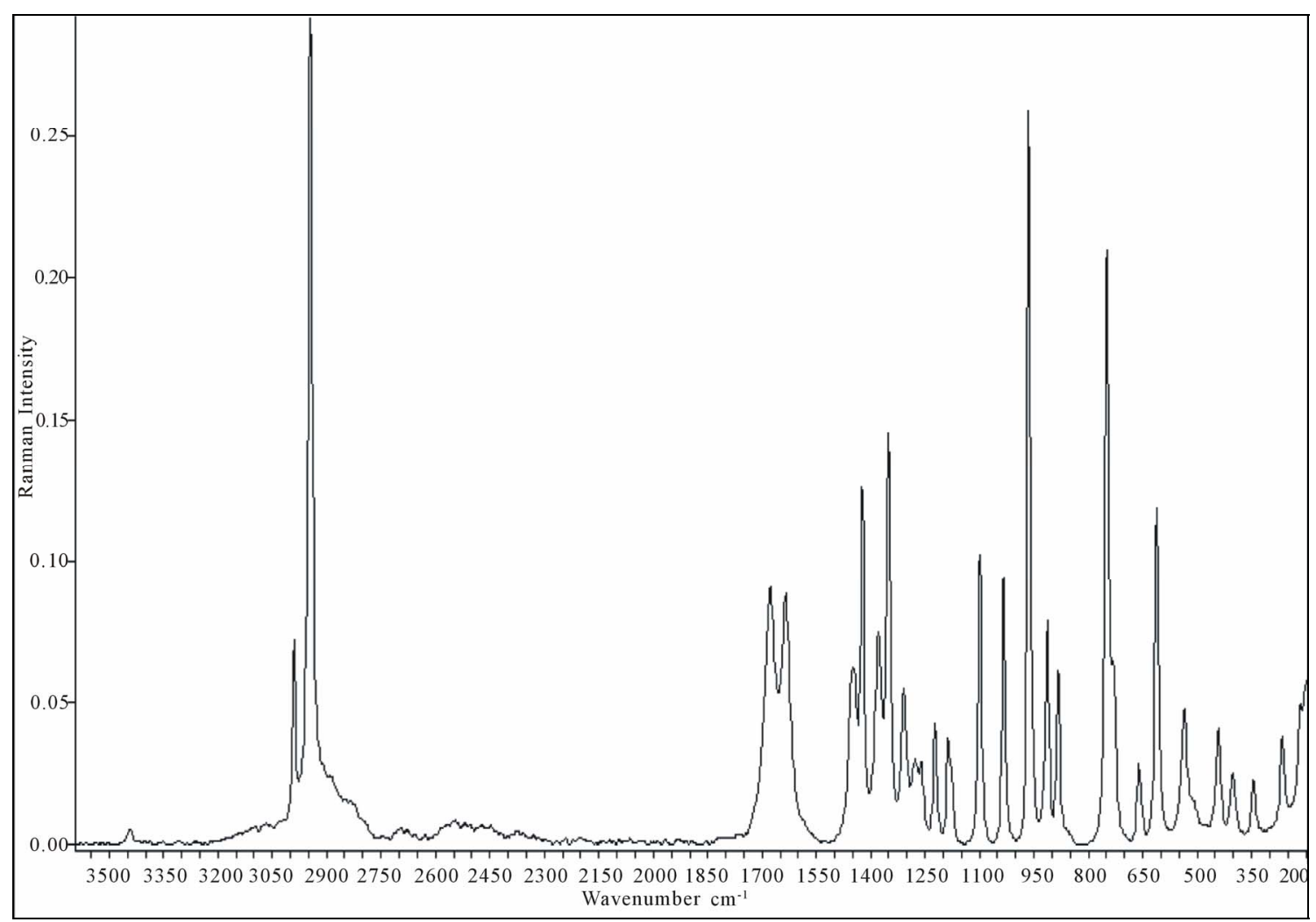

(a)

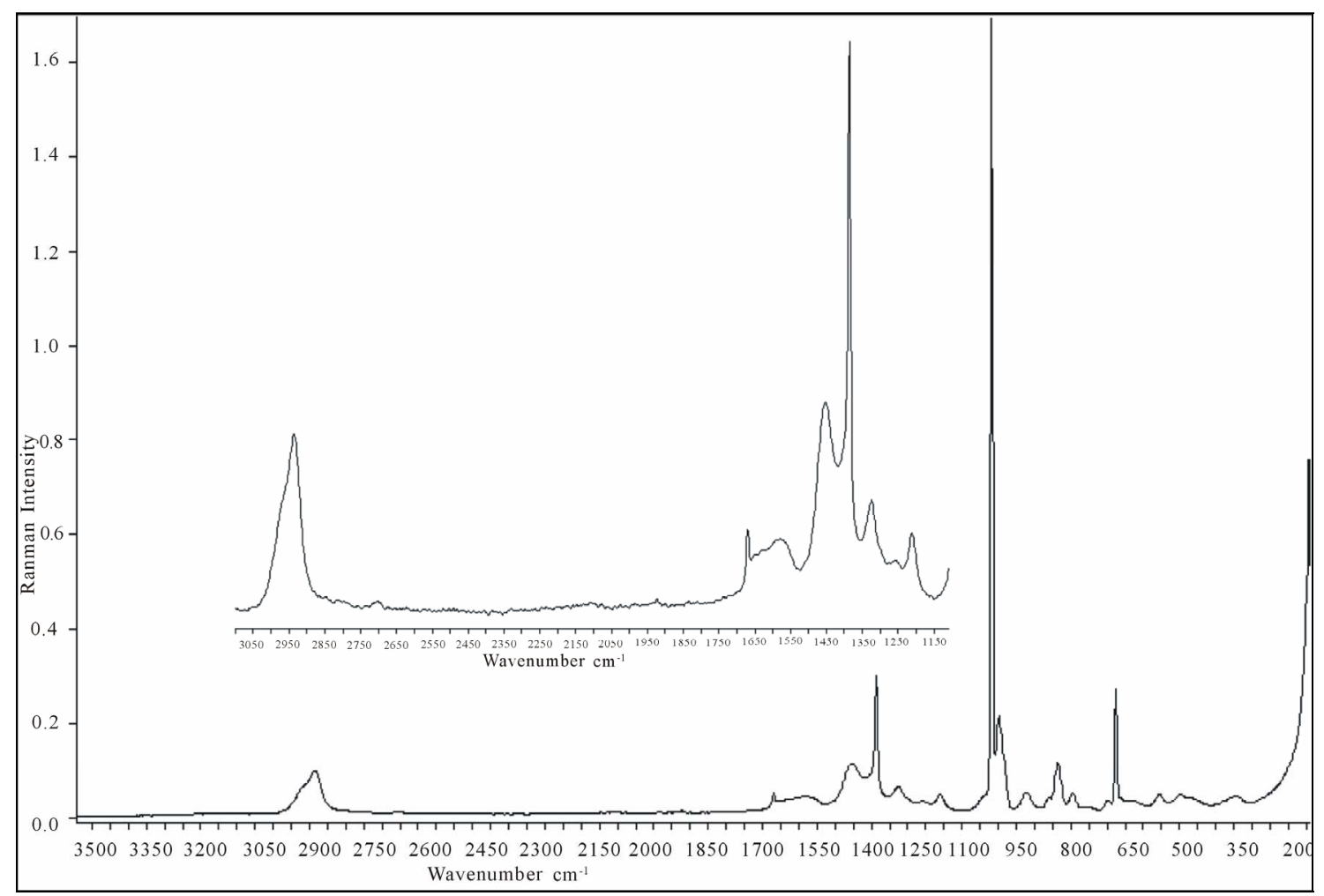

(b)

Figure 7. Experimental FT-Raman spectra in the range $(3600-200) \mathrm{cm}^{-1}$ : (a) free Malic acid; (b) Gd(III)-Malate , $\left[G d^{3+}\right] /\left[L^{2-}\right]=3 / 2$. 


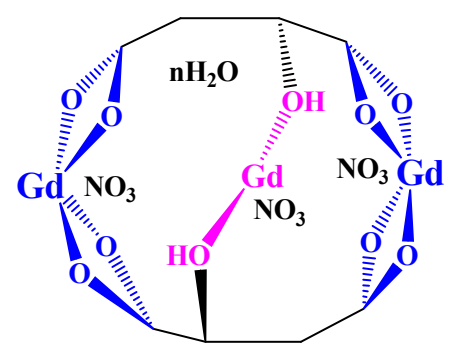

Figure 8. Probable structure for the new trinuclear godolinic complex $\mathrm{Gd}_{3}$ Malte $_{2}\left(\mathrm{NO}_{3}\right)_{3} \cdot n \mathrm{H}_{2} \mathrm{O}$.

complex with a composition $(3,2,3)$ and a high stability $\log _{322}=31.52 \pm 0.05$, has been identified for the interval of studied $\mathrm{pH}$. The results of studies on IR and FT-Raman spectroscopy, clearly show that in this trinuclear complex type of $G d^{3+}$ ions, all oxygens of the two ionized carboxylic functions $\mathrm{COO}^{-}$of malate ion, and the oxygen atom of $\mathrm{OH}$ group in the $\alpha$ position, are involved in chelation sites, while, studies conducted by Hlaïbi et al. $[8,9,27,28]$ show, that for the tungstic complexes of $\alpha$-hydroxyl carboxylic acids, carbonyl function $\mathrm{C}=\mathrm{O}$ is excluded. All these results also indicate, that the combination of these two techniques is very effective for identification and characterization of colourless organometallic complexes of $G d^{3+}$ ions, in fact, is the first time that this tri-nuclear complex was revealed, that its stability has been determined and a probable structure was proposed

\section{Acknowledgements}

All authors wish to thank Professors Jean-François Verchère from the University of Rouen (France) for his advice, fruitful discussions, strong encouragement and exemplary cooperation, and AUF for its financial support.

\section{REFERENCES}

[1] R. D. Rocklin, "Detection in Ion Chromatography," Journal of Chromatography A, Vol. 546, No. 1-2, 1991, pp. 175-187.

[2] J. F. Verchère and A. M. Dona, "Exchange Methods for the Indirect Photometric Determination of Anions and Organic Molecules," Analusis, Vol. 20, No. 8, 1992, pp. 437-450.

[3] S. E. Meek and D. J. Pietrzyk, "Liquid Chromatographic Separation of Phosphorus Oxo Acids and Other Anions with Post-Column Indirect Fluorescence Detection by Aluminum-Morin," Analytical Chemistry, Vol. 60, No. 14, 1988, pp. 1397-1400. doi:10.1021/ac00165a010

[4] P. Morin, C. François and M. Dreux, "Séparation de Cations et d'Anions Inorganiques par Éléctrophorèse Capillaire Ionique Avec une Détection Spectrométrique UV Indirecte: Capillary Electrophoresis of Inorganic Cations and Anions with Different Carrier Electrolytes and UV Detection ," Analusis, Vol. 22, No. 4, 1994, pp.
178-187.

[5] A. M. Lisi, "La Photomertie Indirecte Comme Methode Analytique Pour Letude des complexes incolores des Acides Organiques dans les Solutions Diluées," ParisVI University, Paris, 1993.

[6] M. Hlaibi, "La Photométrie Indirecte et RMN Pour l'Etude de l'Oxalate Urinaire et Pour l'Etude des Complexes Incolore des Ions UO22+ et WO42-," Hassan II University, Ain Chock, Casablanca, 1995.

[7] A. Ramshing, J. Rusika and E. H. Hasen, "A New Approach to Enzymatic Assay Based on Flow-Injection Spectrophotometry with Acid-Base Indicators," Analytica Chimica Acta, Vol. 114, 1980, p. 165-181.

[8] M. Hlaïbi, S. Chapelle, M. Benaissa and J. F. Verchère, "Structures and Stabilities of Tungstate Complexes of .Alpha.-Hydroxy Acids. 183W NMR Study of the Influence of Ligand Substitutionm," Inorganic Chemistry, Vol. 34, No. 17, 1995, pp. 4434-4440. doi: $10.1021 / \mathrm{ic} 00121 \mathrm{a} 022$

[9] M. Hlaïbi, M. Benaissa, C. Busatto, J. F. Verchère and S. Chapelle, "A 13C and 183W NMR Study of Acid as a Multisite Ligand in Tungstate Complexes," Carbohydrate Research, Vol. 278, No. 2, 1995, p. 227. doi:10.1016/0008-6215(95)00266-9

[10] A. Nonat, C. Gateau, P. H. Fries and M. Mazzanti, "Lanthanide Complexes of a Picolinate Ligand Derived from 1,4,7-Triazacyclononane with Potential Application in Magnetic Resonance Imaging and Time-Resolved Luminescence Imaging," Chemistry, A European Journal, Vol. 12, No. 27, 2006, pp. 7133-7150. doi:10.1002/chem.200501390

[11] N. Chatterton, C. Gateau, M. Mazzanti, J. Pécaut, A. Borel and A. Merbach, "The Effect of Pyridinecarboxylate Chelating Groups on the Stability and electronic Relaxation of Gadolinium Complexes," Journal of the Chemical Society, Dalton Transactions, Vol. 21, No. 6, 2005, pp. 1129-1135.

[12] I. Kostova, G. Momekov and P. Stancheva, "New Samarium(III), Gadolinium(III), and Dysprosium(III) Complexes of Coumarin-3-Carboxylic Acid as Antiproliferative AgentsMetal-Based Drugs," Vol. 2007, 2007, 8 pages. doi:10.1155/2007/15925

[13] F. J. Langmyhr and K. S. Klausen, "Complex Formation of Iron (III) with Chrome Azurol S," Analytica Chimica Acta, Vol. 29, 1963, pp. 149-167. doi:10.1016/S0003-2670(00)88596-7

[14] A. M. Dona and J. F. Verchère, "Analytical Applications of Oxocarbons. Part 3. Specific Spectrophotometric Determination of Oxalic Acid by Dissociation of the Zirconium(IV)-Chloranilate Complex," Analyst, Vol. 116, 1991, pp. 533-536. doi:10.1039/an9911600533

[15] M. Malt, "Dissoziationskonstanten von Chromazurol S," Analytica Chimica Acta, Vol. 25, No. 1, 1961, pp. 289291.

[16] W. Hummel, U. Berner, E. Curti, F. J. Pearson and T. Thoenen, "Nagra/PSI Chemical Thermodynamic Data Base 01/01," Radiochimica Acta, Vol. 90, No. 9-11, 2002, pp. 805-813. doi:10.1524/ract.2002.90.9-11_2002.805 
[17] J. D. Robert and M. C. Caserio, "Problème de Chimie Organique Moderne, ”InterEditions, Paris, 1979, p. 32.

[18] Colthup, Daly, Wiberley, Introduction to Infrared and Raman Spectroscopy, Academic Press, New York, 1990.

[19] N. P. G. Roeges, "A Guide to the Complete Interpretation of Infrared Spectra of Organic Structures," Wiley, New York, 1994.

[20] N. Sundaraganesan, B. D. Joshua, M. Rajamoorthy and C. H. Gangadhar, "FT-IR, FT-Raman Spectra and Ab-Initio DFT Vibrational Analysis of 2-Chloro-5-Aminopyridine," Indian Journal of Pure \& Applied Physics, Vol. 45, No. 12, 2007, pp. 969-978

[21] Horiba Jobin Yvon Inc., 3880 Park Avenue, Edison, NJ 08820-3012. USA

[22] E. Smith and G. Dent, "Modern Raman Spectroscopy-A Practical Approach,” Wiley, 2005, pp. 15-19.

[23] N. Sundaraganesana, S. Ilakiamania, H. Saleema, Piotr. M. Wojciechowskib and D. Michalsk, "FT-Raman and FT-IR Spectra, Vibrational Assignments and Density Functional Studies of 5-Bromo-2-Nitropyridine," Spectrochimica Acta, Part A, Vol. 61, No. 13-14, 2005, pp. 2995-3001.

[24] L. Padmaja, T. Vijayakumar, I. H. Joe, C. P. R. Nair and V. S. Jayakumar, "Vibrational Spectral Studies and the Non-Linear Optical Properties of a Novel NLO Material

\section{Abbreviations}

IPD: Indirect Photometric Detection

MRI: Magnetic Resonance Imaging,

$\mathbf{H}_{4}$ Ch: Chrome Azurol S,

MESH: 2-(N-morpholino) sulphonic ethane acid.

$\boldsymbol{A}_{I}$ and $\boldsymbol{A}_{\boldsymbol{F}}$ : The absorption values for the undissociated and the totally dissociated sacrificial complex.

$\boldsymbol{K}_{x y z}^{\prime}$ : The apparent formation constant

$\boldsymbol{K}_{x y z}$ : The formation constant (or stability constant)
L-Prolinium Tartrate," Journal of Raman Spectroscopy, Vol. 37, No. 12, 2006, pp. 1427-1441.

doi:10.1002/jrs. 1575

[25] S. Gunasekaran and S. Ponnusaymy, "Vibrational Spectra and Normal Coordinate Analysis on an Organic NonLinear Optical Crystal-3-methoxy-4-hydroxy Benzaldehyde," Indian Journal of Pure \& Applied Physics, Vol. 43, No. 11, 2005, pp. 838-843.

[26] K. Malek, E. Podstawka, J. Milecki, G. Schroeder and L. M. Proniewicz, "Structural Features of the Adenosine Conjugate in Means of Vibrational Spectroscopy and DFT," Biophysical Chemistry, Vol. 142, No. 1-3, 2009, pp. 17-26. doi:10.1016/j.bpc.2009.02.007

[27] S. Chapelle, J. P. Sauvage, P. Köll and J. F. Verchère, "183W NMR Studies of Tungstate Complexes of Carbohydrates. 3. Species Formed with All-threo Alditols Acting as Tridentate, Tetradentate, or Pentadentate Ligands," Inorganic Chemistry, Vol. 34, No. 4, 1995, pp. 918-923. doi:10.1021/ic00108a024

[28] M. Hlaïbi, M. Hor, M. Riri, A. Benjjar and J. F. Verchère, "Multinuclear ${ }^{183} \mathrm{~W}$ and ${ }^{13} \mathrm{C}$ NMR and Indirect Photometry Study for the Identification and the Characterization of New Complexes of Sugar Acids," Journal of Molecular Structure, Vol. 920, No. 1-3, 2009, pp. 310-322. doi:10.1016/j.molstruc.2008.11.016

$\mathbf{L}^{2-}$ : The ligand (malate ion)

$C_{\mathrm{L}}$ : The analytical concentration of the ligand

$C_{\mathbf{H C h}}$ : The analytical concentration of ligand $\mathbf{H C h}^{3-}$ in all its forms

$\boldsymbol{C}_{\mathrm{Gd}}$ : The initial gadolinium concentration

$\mathbf{G d}_{3} \mathbf{H C h}_{2}$ : The sacrificial colored complex

q: The molar ratio (gadolinium/malate ion). 